\title{
Effects of Microwave - Induced Torrefaction on Waste Straw Upgrading
}

\author{
Yi-Li Lin
}

\begin{abstract}
This study focused on upgrading waste straw by developing the technology of microwave-imduced torrefaction and investigating the key operating parameters to improve the energy density and hydrophobicity of biomass for better feedstock for the production of renewable energy. The experiments were conducted under inert environment and atmospheric pressure in a fixed-bed batch reactor putting in a self-designed microwave facility. Factors including microwave power $(250$ to $450 \mathrm{~W})$, reaction time $(10$ to $30 \mathrm{~min})$ and moisture content (8 to $50 \%$ ) were evaluated and the torrefaction temperature was monitored and controlled in the range of 200 to $300{ }^{\circ} \mathrm{C}$. It was found that the shape and fullness of the reactor as well as the position and direction of the thermocouple in the microwave facility significantly affected the efficacy of microwave-induced torrefaction, while the influences of nitrogen flow-rate and moisture content of the biomass were negligible. With the increase of microwave power from 250 to $450 \mathrm{~W}$, the content of fixed carbon and ash, higher heating value (HHV) and energy density increased in the torrefied straw. TGA and DTG confirmed the evaporation of moisture as well as the decomposition of hemicellulose and cellulose in biomass structures, and microwave power was the key factor affecting the torrefaction temperature so as to the energy yield and density of torrefied biomass. Straw torrefied under $450 \mathrm{~W}$ for 30 min showed characteristics similar to those of blended coal with HHV approaching to that of bituminous coal. With further optimization of microwave torrefaction parameters (power and reaction time), torrefied straw has potential for the substitution of coal used in pulverized coal-fired furnace.
\end{abstract}

Index Terms-Microwave-induced torrefaction, rice straw, energy density, thermogravimetric analysis.

\section{INTRODUCTION}

Biomass is one of the most renewable energy sources supplying $12 \%$ energy in the world after proper pretreatment for the generation of electricity as well as production of ethanol [1]. However, untreated biomass possessed the characteristics of low energy density, high heterogeneity, high water content and difficult for preservation and size reduction, which make it hard to be utilized directly in pulverized firing systems [2]. Torrefaction, a thermo-chemical process, involves heating biomass in inert atmosphere at temperatures of $200-300^{\circ} \mathrm{C}$, during which biomass undergoes dehydration and decarboxylation reactions [3]. The torrefied biomass contains high energy density, hydrophobicity and grindability, which can save significant cost in the transportation and size reduction, increase the efficiency in direct combustion [4], [5], and offer

Manuscript received January 31, 2015; revised March 25, 2015.

Y. L. Lin is with the National Kaohsiung First University of Science and Technology, Kaohsiung 824, Taiwan (e-mail: yililin@ @kfust.edu.tw). an option for carbon sequestration for climate change mitigation [6].

As one of the most important food crops, the annual production of rice is over 700 million tons in this decade. Around 1 billion tons of rice straw is generated, but most of which is wasted with out recycle or further usage.

Microwave-induced torrefaction is a new technology that presents many advantages over traditional heating such as selective and controllable as well as energy and cost efficient without direct contact with heated matter [7]. However, very few studies focused on Microwave-induced torrefaction but microwave pyrolysis [1], [7]. Therefore, the objectives of this research were (1) to build up and modify the microwave setup for torrefaction, (2) to study the effect of operating factors on the characteristics of torrefied rice straw, including microwave power, reaction time and moisture content in raw rice straw and (3) to study the decomposition mechanisms of rice straw during microwave-induced torrefaction.

\section{MATERIALS AND METHODS}

Raw rice straw was collected from the field in southern Taiwan, dried in an oven at $105^{\circ} \mathrm{C}$ for $24 \mathrm{hr}$, grinded and sieved using the screen size of 30 mesh $(0.60 \mathrm{~mm})$ and then stored in a dessicator at room temperature until usage. The raw straw was conditioned to the designed moisture content of 8 to $50 \%$ (db) by uniformly spraying water into the sieved grinds and storing in a plastic bag in a controlled environment at $25{ }^{\circ} \mathrm{C}$ for 1 day for moisture equilibrium. The composition of raw and torrefied straw was determined by proximate analysis following the ASTM Standard method D5142, ultimate analysis using an elemental analyzer (Elementar Vario EL III, Germany), and heating value using a bomb calorimeter (Parr Model 1108 Oxygen Bomb, USA). The characteristics of the raw biomass are summarized in Table I, where VM is volatile matter, FC is fixed carbon and $\mathrm{db}$ is dry basis). The decomposition of raw and torrified straw was determined by thermogravimetric analysis (TGA) and derivative thermalgravimetric (DTG) analysis (TGA/SDTA 851, Mettler-Toledo, Switzerland).

TABLE I: THE CHARACTERISTICS OF RAW STRAW.

\begin{tabular}{|c|c|c|c||c|c|c|c|c|c|}
\hline \multicolumn{3}{|c|}{ Proximate analysis (wt \%) } & \multicolumn{5}{|c|}{ Ultimate analysis (wt\%, db) } & HHV \\
\hline Moisture & VM & FC & Ash & C & H & N & S & O & $(\mathrm{kcal} / \mathrm{kg})$ \\
\hline 8.3 & 75.5 & 8.4 & 7.7 & 39.9 & 5.7 & 0.4 & 0.1 & 53.9 & 3746 \\
\hline
\end{tabular}

The schematic setup of the microwave-induced torrefaction unit was shown in Fig. 1. The set up was developed using a microwave cavity oven but replacing the microwave source with a $2.45 \mathrm{GHz}$ adjustable $(0-1000 \mathrm{~W})$ 
and constant output one. In each experiment, $10 \mathrm{~g}$ prepared samples was put in a crucible in a custom-made cylindrical pyrex container (103 $\mathrm{mm}$ in diameter and $180 \mathrm{~mm}$ in height), which was placed in the center of the microwave cavity. A K-type thermocouple was grounded with stainless steel metal sheath and covered with a Teflon tube throughout the microwave cavity with only the tip exposed inside the biomass sample to avoid the interference of microwave reflection with temperature measurements. The container was sealed by adding a cover on the top of it, a close fitting silicon o-ring in between, and paper tape on the side of joint [8]. A constant flow of nitrogen gas was purged through a port at the bottom of the reactor to keep an inert atmosphere and carry out gas products in the reactor. Three operation parameters including microwave power (250 to $450 \mathrm{~W})$, reaction time (10 to $30 \mathrm{~min}$ ) and moisture content (8 to $50 \%$ ) were evaluated with the torrefaction temperature monitored and controlled in the range of 200 to $300^{\circ} \mathrm{C}$. After reaching the designed reaction time, the power was turned off but kept purging nitrogen gas until the temperate cooled down to under $100^{\circ} \mathrm{C}$.

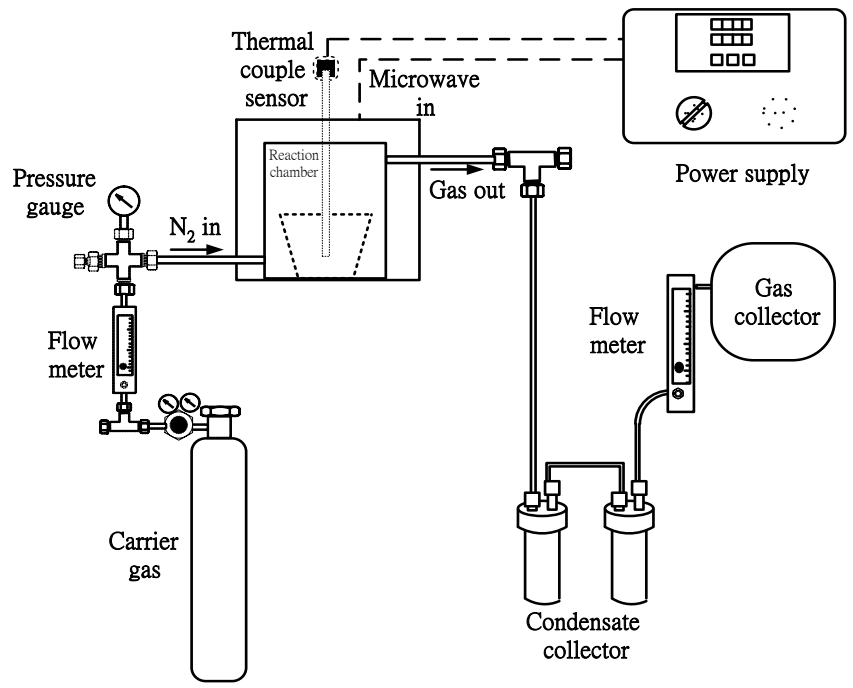

Fig. 1. The schematic setup of the microwave-induced torrefaction unit.

The microwave power was calibrated by microwaving $1 \mathrm{~L}$ DI water in a glass container in the middle of cavity for $2 \mathrm{~min}$, recording the temperature raise and calculating the energy balance.

\section{RESUlTS AND DISCUSSION}

\section{A. Pretest of Designed Setup}

Among all the combination of tested parameters including microwave power (250-450 W), microwave time (10-60 $\mathrm{min})$, nitrogen flow rate $(10-50 \mathrm{~mL} / \mathrm{min})$, moisture content of raw rice straw $(8-50 \%)$, and the dosage of activated carbon as microwave absorber ( $20 \%$ wt. of biomass), the temperature in the middle of biomass can not reach the required 200-300 ${ }^{\circ} \mathrm{C}$ torrefaction temperature. Moreover, in each experiment, the condensable volatiles were condensed on the wall of container instead of being collected outside the microwave chamber in the condensate collector. Therefore, the microwave-induced torrefaction unit was modified and shown in Fig. 2. The thermal couple was placed from the side of container and covered with a Teflon tube throughout the microwave cavity with only the tip exposed inside the middle of biomass sample. The container was modified with wider top space and fillister around (150 $\mathrm{mm}$ in diameter) to separate the condensate and torrefied biomass. The nitrogen flow rate was controlled at $10 \mathrm{~mL} / \mathrm{min}$, and $50 \mathrm{~g}$ biomass was placed in the bottom of container directly. In this way, the temperature can be controlled and reached the required torrefaction range.

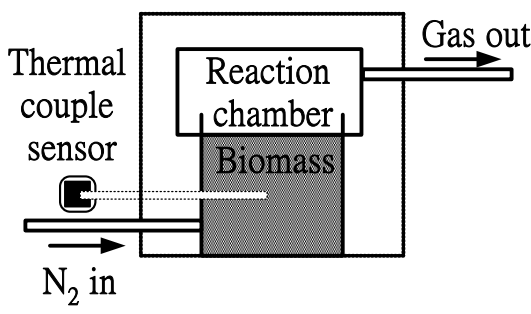

Fig. 2. The modified setup of the container.

Fig. 3 shows the temperature profile and microwave power of raw rice straw during microwave-induced torrefaction. The temperature increased rapidly in the first $10 \mathrm{~min}$, reached $200^{\circ} \mathrm{C}$ in $19 \mathrm{~min}$ and maintained above $200^{\circ} \mathrm{C}$ in the following $30 \mathrm{~min}$. In this experiment, the reaction time was recorded as $30 \mathrm{~min}$. The heating rate met the torrefaction requirement of below $50^{\circ} \mathrm{C} / \mathrm{min}$ [2]. Therefore, the modification of the setup was considered successful and applied for the following experiments with microwave power of $250-450 \mathrm{~W}$, reaction time of $10-30 \mathrm{~min}$ and moisture content of $8-50 \%$, and the results are shown in the following sections.

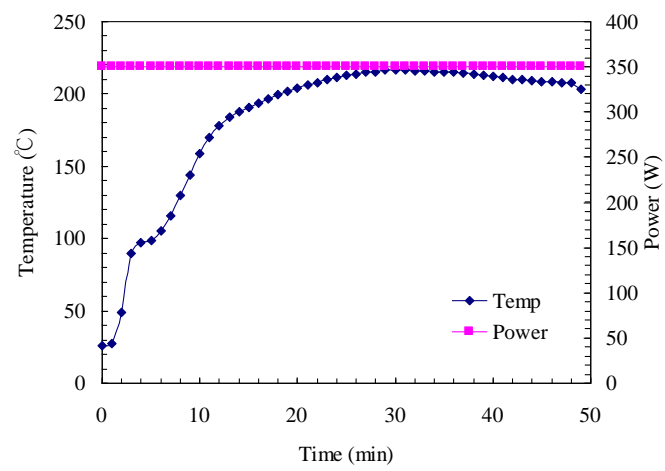

Fig. 3. Temperature profiles and microwave power of raw rice straw during microwave-induced torrefaction.

\section{B. Confirmation of the Key Operating Factors}

Fig. 4 shows the composition of raw and torrefied rice straw with reaction time of $30 \mathrm{~min}$ in the van Krevelen diagram. It is noteworthy that with the increase of microwave power but reduce of moisture content, the atomic $\mathrm{H} / \mathrm{C}$ and $\mathrm{O} / \mathrm{C}$ ratio of torrefied biomass approaches to those of coal, with microwave-induced torrefaction at $350 \mathrm{~W}, 8 \%$ moisture content biomass, $350 \mathrm{~W}, 3 \%$ moisture content biomass, and $400 \mathrm{~W}, 30 \%$ moisture content biomass showed characteristics similar to those of peat. Therefore, by increasing microwave power with moisture content less than $30 \%$, rice straw has potential for being used in pulverized coal-fired furnace as renewable bioenergy. 


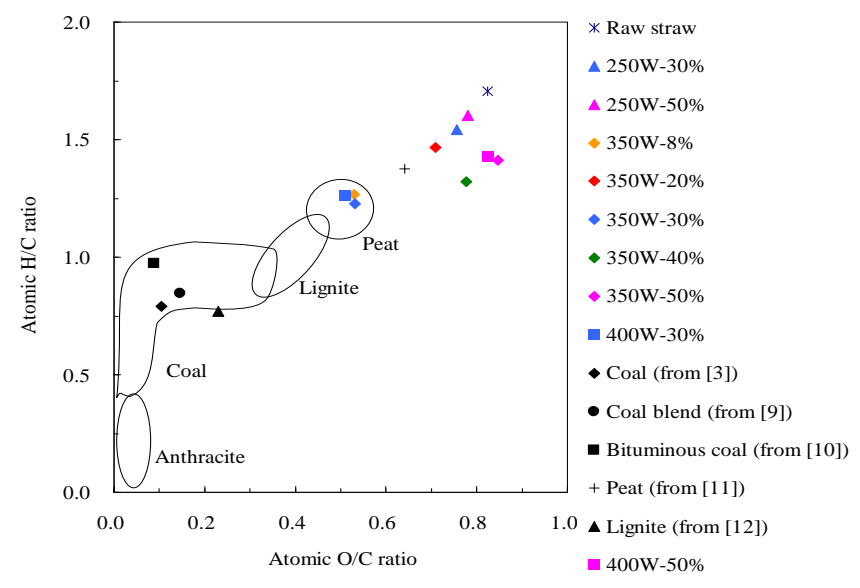

Fig. 4. The Van Krevelen diagram of raw and 30 min microwave-induced torrefied rice straw.

\section{Characteristics of the Torrefied Biomass}

In the following experiments, the raw rice straw was torrefacted under high microwave power $(350-450 \mathrm{~W})$, reasonable reaction time $(10-30 \mathrm{~min})$ and low moisture content $(8-20 \%)$ according to the conclusions got in the previous section. The values of proximate analysis of torrefied biomass are shown in Fig. 5. The moisture content in the torrefied straw significantly decreased while the FC increased in all cases. The impact of microwave power was more significant than that of moisture content. On the other hand, higher moisture content in the raw straw led to higher ash content but lower VM in the torrefied biomass. It was also reported in the microwave pyrolysis of willow chips and straw that preferentially generated liquid and gases [1], [7], [13], [14].

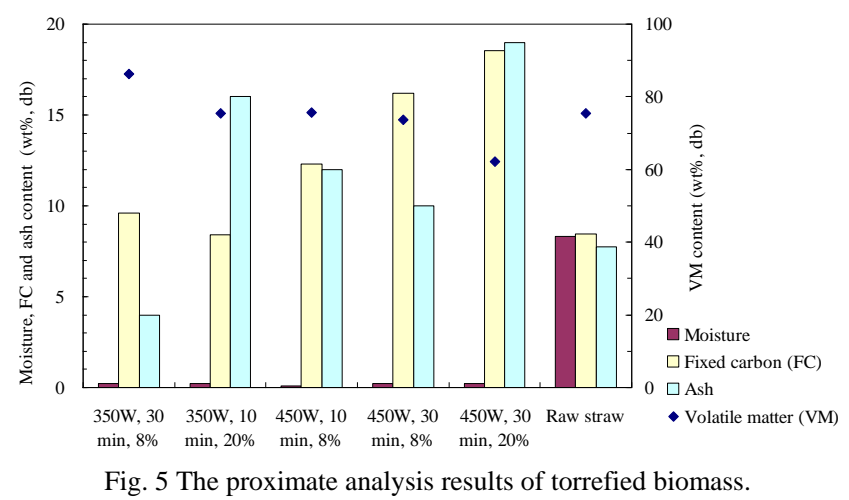

The mass yield, energy yield and energy density of the torrefied biomass were calculated according to Eqs. (1) to (3) and are shown in Fig. 6.

$$
\begin{aligned}
& \text { Mass yield }(\%)=\left(\text { Mass }_{\text {torrefied sample }} / \text { Mass }_{\text {raw sample }}\right) \times 100 \% \\
& \text { Energy yield }(\%)=\left(\text { Mass yield } \times H H V_{\text {torrefied }}\right) / \mathrm{HHV}_{\text {raw sample }}(2) \\
& \text { Energy density }(-)=\text { Energy yield/Mass yield }
\end{aligned}
$$

As shown in Fig. 6, higher moisture content and reaction time led to lower mass and energy yield but higher energy density in the torrefied solid, which could be due to the escape of volatiles with low heating values. At the same reaction time and moisture content, higher microwave power led to lower mass and energy yield but higher energy density. Moreover, the HHV of all the torrefied solid products reached 20-24 MJ/kg, which overtake that of blend coal (17 $\mathrm{MJ} / \mathrm{kg}$ [9]) and approach that of bituminous coal (28 MJ/kg [10]). High microwave power $(450 \mathrm{~W})$ with long reaction time (30 min) maintained only $23-33 \%$ solid products and $35-45 \%$ energy yield. Considering energy conservation and the maintenance of solid biomass for $60 \% \mathrm{wt}$, the recommended operating parameters would be $350 \mathrm{~W}, 10-30$ min reaction time and $8-20 \%$ moisture content, $450 \mathrm{~W}, 10$ min reaction time and $8 \%$ moisture content.

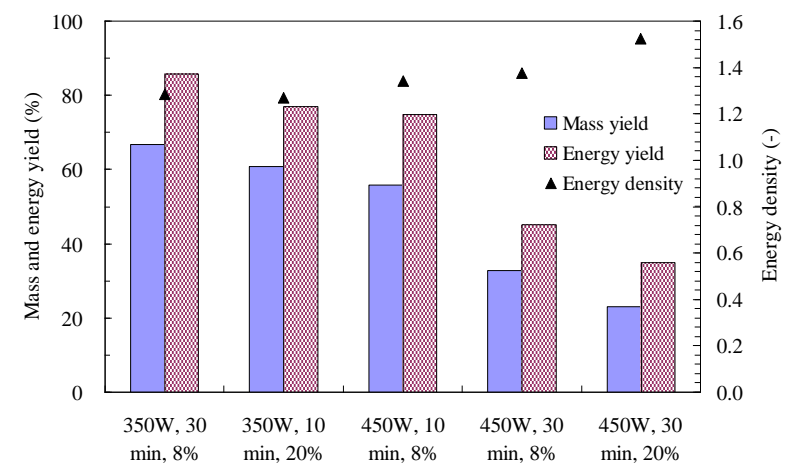

Fig. 6. The mass and energy yield as well as energy density of torrefied biomass.

The analyses of TGA and DTG provide a deeper insight of the thermal-stability and degradation mechanisms of raw and torrefied solid biomass, and the results are shown in Figs.7 and 8 . According to our pretest, the weight loss over $500^{\circ} \mathrm{C}$ was very low so that the TGA and DTG analyses for the raw and torrefied straw were operated under $500^{\circ} \mathrm{C}$. In Fig. 7, the weight loss was low for the $20 \%$ moisture content cases, which can be explained by the high ash content in Fig. 5 . According to Chen and Kao [15], slight weight loss (less than $10 \%$ ) at temperature below $200^{\circ} \mathrm{C}$ was due to the release of moisture and some light volatiles. Significant weight loss was observed at temperature between 200 and $500^{\circ} \mathrm{C}$ due to thermal decomposition of hemicellulose, cellulose and lignin, which can be confirmed in the DTG curves in Fig. 8.

In Fig. 8, the curve area of raw straw is large, with two overlap peaks at 300 and $350^{\circ} \mathrm{C}$, which stand for the thermal decomposition of hemicellulose and cellulose, respectively [15]. Biomass with high moisture content (20\%) has small covered area. On the other hand, there is only one peak for all torrefied solid products at $345^{\circ} \mathrm{C}$, which inferred that the retention of some cellulose and lignin parts.

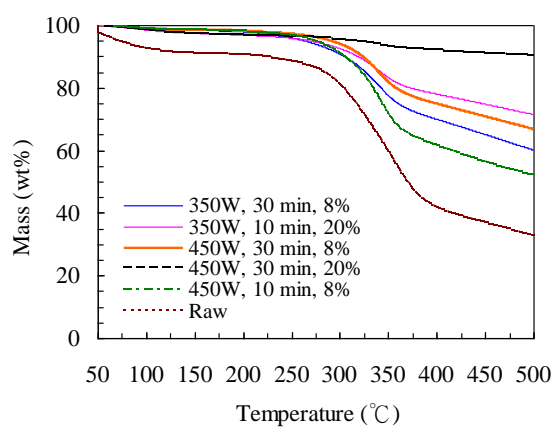

Fig. 7. The TGA analysis of rice straw before and after microwave-induced torrefaction. 


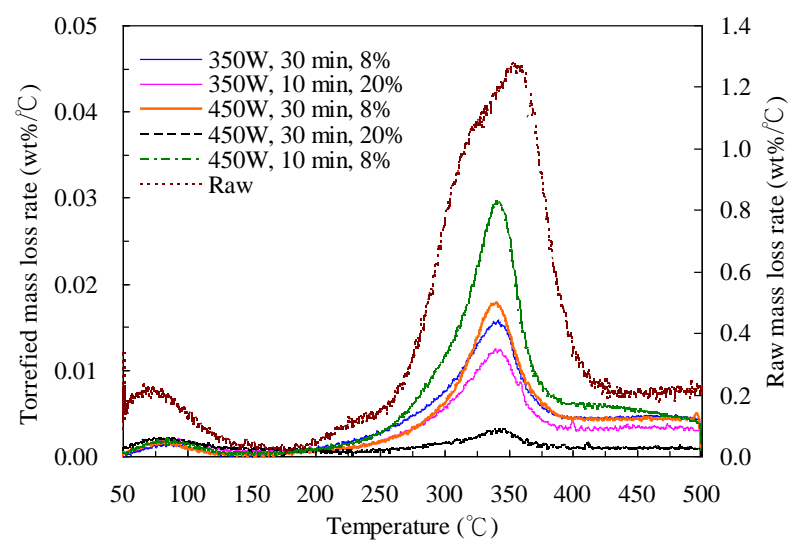

Fig. 8. The DTG analysis of rice straw before and after microwave-induced torrefaction.

\section{ACKNOWLEDGMENT}

The author thanks the Ministry of Science Council in Taiwan for the financial support (102-2221-E-327-021).

\section{REFERENCES}

[1] S .Ren, H. Lei, G. Yadavalli, Y. Liu, and J. Julson, "The integrated process of microwave torrefaction and pyrolysis of corn stover for biofuel production," J. Anal. Appl. Prol., vol. 108, pp. 248-253, 2014.

[2] L. J. R. Nunes, J. C. O. Matias, and J. P. S. Catalăo, "A review on torrefied biomass pellets as a sustainable alternative to coal in power generation," Rene Sustainable Energy Rev., vol. 40, pp. 153-160, 2014.

[3] H. Li, X. Liu, R. Legros, X. T. Bi, C. J. Lim, and S. Sokhansanj, "Torrefaction of sawdust in a fluidized bed reactor," Bioresou. Technol., vol. 103, pp. 453-458, 2012.

[4] Y. L. Lin and H. Lien, "Impact of torrefaction on the physicochemical properties of agricultural biomass," presented at the 6th International Conference on Applied Energy, Taipei, Taiwan, May 30 - June 2, 2014.

[5] Y. L. Lin and C. W. Wu, "Impact of torrefaction on the physicochemical properties of woody biomass," in Proc. the International Conference on Frontiers of Environment, Energy and Bioscience, Beijing, China, 2013, pp. 295-300.
[6] D. Woolf, J. E. Amonette, F. A. S. Perrott, J. Lehmann, and S. Joseph, "Sustainable biochar to mitigate global climate change," Nat. Commun., vol. 1, pp. 1-9, 2010

[7] O. Mašek, V. Budarin, M. Gronnow, K. Crombie, P. Brownsort, E. Firzpatrick, and P. Hurst, "Microwave and slow pyrolysis biochar-Comparison of physical and functional properties," J, Anal. Appl. Pyrolysis, vol. 100, pp. 41-48, 2013.

[8] S. K. Satpathy, L. G. Tabil, V. Meda, S. N. Naik, and R. Prasad, "Torrefaction of wheat and barley straw after microwave heating," Fuel, vol. 124, pp. 269-278.

[9] J. Pallarés, A. Gil, C. Cortés, and C. Herce, "Numerical study of co-firing coal and Cynara cardunculus in a 350 MWe utility boiler," Fuel Pro. Technol., vol. 90, pp. 1207-1213, 2009.

[10] M. Phanphanich and S. Mani, "Impact of torrefaction on the grindability and fuel characteristics of forest biomass," Bioresou. Technol., vol. 102, pp. 1246-1253, 2011.

[11] M. Hirai, M. Ohtake, and M. Shoda, "Removal kinetics of hydrogen sulfide, methanethiol and dimethyl sulfide by peat biofilters," $J$. Ferment. Bioeng., vol. 70, pp. 334-339, 1990.

[12] J. Parikh, S. A. Channiwala, and C. H. Ghosal, "A correlation for calculating HHV from proximate analysis of solid fuels," Fuel, vol. 84 pp. 487-494, 2005.

[13] Y. F. Huang, P. T. Chiueh, W. H. Kuan, and S. L. Lo, "Microwave pyrolysis of rice straw: Products, mechanism, and kinetics," Bioresour. Technol., vol. 142, pp. 620-624, 2013.

[14] B. Moghtaderi, C. Meesri, and T. F. Wall, "Pyrolytic characteristics of blended coal and woody biomass," Fuel, vol. 83, pp. 745-750, 2004.

[15] W. H. Chen and P. C. Kuo, "Torrefaction and co-torrefaction characterization of hemicellulose, cellulose and lignin as well as torrefaction of some basic constituents in biomass," Energy, vol. 36, pp. 803-811, 2011.

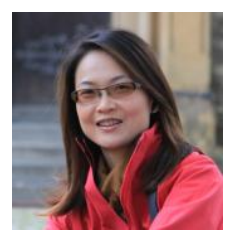

Yi-Li Lin received her Ph.D. in environmental engineering and B.S. in civil engineering from the National Taiwan University in 2007 and 1999, respectively.

Prior to joining NKFUST as an assistant professor, she engaged in post-doctoral research at the National Taiwan University during 2007-2008 and the Stanford University during 2008-2009. Her research is focused on physical and chemical processes for water treatment and water pollution control as well as development of torrefaction technology for waste biomass. Dr. Lin owns the membership of CBEES. 